\title{
Management of psychiatric disorders in Parkinson's disease
}

\section{Neurotherapeutics - Movement Disorders Therapeutics}

\author{
Daniel Weintraub ${ }^{1,2}$ (D) \\ Published online: 8 June 2020 \\ (C) The American Society for Experimental NeuroTherapeutics, Inc. 2020
}

\begin{abstract}
Affective disorders (depression and anxiety), psychosis, impulse control disorders, and apathy are common and sometimes disabling psychiatric conditions in Parkinson disease (PD). Psychiatric aspects of PD are associated with numerous adverse outcomes, yet in spite of this and their high frequency, there remains incomplete understanding of epidemiology, presentation, risk factors, neural substrate, and management strategies. Psychiatric features are typically co- or multimorbid, and there is great intra- and interindividual variability in presentation [1]. The neuropathophysiological changes that occur in PD, as well as the association between PD treatment and particular psychiatric disorders, suggest a neurobiological contribution to many psychiatric symptoms. There is evidence that psychiatric disorders in PD are still under-recognized and undertreated, and although psychotropic medication use is common, randomized controlled trials demonstrating efficacy and tolerability are largely lacking. Future research on neuropsychiatric complications in PD should be oriented toward determining modifiable correlates or risk factors, and most importantly, establishing efficacious and well-tolerated treatment strategies.
\end{abstract}

Keywords Psychiatry $\cdot$ Depression $\cdot$ Anxiety $\cdot$ Psychosis $\cdot$ Impulse control disorders $\cdot$ Apathy

\section{Introduction}

James Parkinson may have described depression as a feature of what eventually came to be called Parkinson disease (PD) [2], but careful study of his disease-defining essay finds that none of his six illustrative cases had any psychiatric symptoms [3]. It has only been in the past half-century, with the introduction of levodopa and other PD medications and treatments into clinical practice, the increasing life span of both the general population and $\mathrm{PD}$ patients, and increasing awareness and clinical research, that neuropsychiatric symptoms or disorders (hereafter combined and abbreviated NPS), and non-motor symptoms more broadly (including cognitive impairment and dementia) [4], have been recognized as being very common and disabling long-term motor symptoms. In addition,

Daniel Weintraub

daniel.weintraub@pennmedicine.upenn.edu

1 Psychiatry and Neurology, Perelman School of Medicine at the University of Pennsylvania, Philadelphia, PA, USA

2 Parkinson's Disease Research, Education and Clinical Center (PADRECC), Corporal Michael J. Crescenz Veterans Affairs Medical Center, Philadelphia, PA, USA they are associated with poor long-term outcomes and increased caregiver burden, and requiring special clinical expertise for optimal management [5].

Currently it is estimated that approximately one million persons living in the United States have a PD diagnosis [6]. Although PD is still considered a movement disorder and is diagnosed based on cardinal motor signs and symptoms [7], the high prevalence of numerous NPS suggests that it is more accurately conceptualized as a neuropsychiatric disorder [5]. In addition to the most commonly studied NPS, such as cognitive impairment (both mild cognitive impairment and dementia, covered elsewhere in this series), depression, and psychosis, other relatively common and clinically significant psychiatric complications include impulse control disorders (ICDs), various anxiety symptoms, disorders of sleep and wakefulness (covered elsewhere in this series), and apathy.

As summarized below, the high cumulative prevalence of a large number of NPS in PD does appear to be the result of a "perfect storm", with contributing factors including demographic characteristics (e.g., sex and age), diffuse and multiple neurodegenerative disease pathologies, other neurobiological factors, and even PD treatments themselves. Weathering this storm, including adapting to a rapidly changing PD treatment landscape, will require an ongoing, concerted effort with a 
tripartite focus on research, education and training, and improving clinical care. Given the now irrefutable and overwhelming evidence that PD is a neuropsychiatric disorder, there ensues a responsibility to respond accordingly to improve patients' lives.

\section{Depression}

Depression has been the most widely studied of all psychiatric disorders in PD [5], and major advances have been made in characterizing its frequency, clinical phenotype, and diagnosis. Instead of considering depressed PD (dPD) patients as a homogenous group, recent epidemiological research has reported that the frequency of major (i.e., more severe) depression is $5-20 \%$, with nonmajor forms of depression (i.e., minor depression) occurring in an additional $10-30 \%$ of patients [8-11]. Thus, up to $50 \%$ of PD patients experience depression at some point in the course of their illness, yet not all depressive disorders are severe enough to warrant treatment. In spite of this caveat, there is still evidence that $\mathrm{dPD}$ remains underrecognized and undertreated [12], even in specialty care settings $[13,14]$.

Another advance is our understanding of the numerous correlates, and possibly risk factors, for $\mathrm{dPD}$, including female sex [9], a personal [15] or familial [16] history of depression, early-onset PD [17], "atypical" parkinsonism [10], and psychiatric comorbidity (e.g., worse cognition, psychosis, anxiety, apathy, fatigue, and insomnia) [9,18-21]. There is inconsistent evidence that $\mathrm{dPD}$ is distinct from non-PD depression; some studies report higher rates of anxiety, pessimism, suicide ideation without suicide behavior, and less guilt and selfreproach in dPD patients compared with their non-PD counterparts [22]. However, overall predictors or correlates of depression are similar between populations [23].

Not surprisingly, core nonsomatic symptoms of depression discriminate most highly between depressed and nondepressed patients (i.e., less likelihood of symptom overlap) [24]. It has almost become dogma that suicide is uncommon in PD [25, 26], perhaps related to personality traits (e.g., high neuroticism and harm avoidance, and low openness, extraversion, and novelty-seeking) thought to characterize PD patients overall [27, 28], although the notion of a parkinsonian personality remains controversial, largely because of concerns regarding recall bias in studies performed after PD diagnosis. Yet more recent research challenges this and suggests that both death ideation and suicide ideation, if not completed suicide, may be relatively common, or at least more common than in the general population [29-31].

Depression in PD likely results from a complex interaction of psychological, physical or neurological, and neurobiological factors. The strong association between frequency of depression and severity of PD suggests that disease-related functional impairments or widespread pathology contribute to depression [32, 33]. However, similar rates of depression in PD and equally disabled patients with other diseases, and high rates of depression and depression treatment even at PD onset with mild disease present [34], indicate that psychological factors are also likely important [35]. Finally, supporting the contribution of neurobiological factors are findings that depression may be a prodromal syndrome in some PD patients [36-39].

Biologically, dPD may be related to dysfunction in subcortical nuclei and the prefrontal cortex; striatal-thalamicprefrontal cortex circuitry and the basotemporal limbic circuit; and brainstem monoamine and indolamine (i.e., dopamine, serotonin, and norepinephrine) systems [40-48]. One study found an association between genotypes, specifically the SLC6A15 and TPH2 genes, and dPD [49], but multiple studies examining the serotonin transporter (SERT) and dopamine transporter $(D A T)$ genes have been inconclusive.

An International Parkinson Disease and Movement Disorder Society (IPMDS)-commissioned task force reviewed and made recommendations for the use of depression rating scales in PD [50]. Around the same time, a National Institute of Neurological Disorders and Stroke/National Institute of Mental Health (NINDS/NIMH) work group suggested provisional diagnostic criteria for $\mathrm{dPD}$ [51], proposing modifications that are similar to those for depression in Alzheimer disease $(\mathrm{AD})$ [52].

\section{Management}

Approximately $20-25 \%$ of PD patients are on an antidepressant at any given time, even de novo, untreated patients [1, 53], most commonly a selective serotonin reuptake inhibitor (SSRI) [14, 54]. Antidepressant use increases over the initial years of PD [55].

As recently reviewed and summarized by the IPMDS Evidence-Based Medicine Committee for the treatment of nonmotor symptoms, relatively few randomized controlled trials (RCTs) for dPD have been published [56]. However, there is now evidence from several relatively recent RCTs that tricyclic antidepressants (TCA; nortriptyline and desipramine) $[57,58]$, a selective serotonin reuptake inhibitor (SSRI, paroxetine) and a serotonin and norepinephrine reuptake inhibitor (SNRI, venlafaxine) [59] are all relatively efficacious in the treatment of dPD. However, it must be noted that in the pivotal SAD-PD study [59] the differences between active (paroxetine and venlafaxine) and placebo treatments for dichotomous outcomes (i.e., response and remission rates) were not statistically significant. In addition, TCAs need to be used cautiously in PD in light of their anticholinergic effects and potential cardiotoxicity, of particular concern in the event of an overdose. 
In another small RCT, atomoxetine (a selective norepinephrine reuptake inhibitor that is approved by the United States Food and Drug Administration (FDA) for the treatment of attention-deficit/hyperactivity disorder) was not clearly efficacious for depression, but was associated with improvement in global cognitive performance and daytime sleepiness [60].

In terms of the effects of PD medications, a dopamine agonist (DA; pramipexole) study for depressive symptoms in PD was positive [61], but a different DA (rotigotine patch) study was negative [62]. There was an initial suggestion of an antidepressant effect for an monoamine oxidase B (MAO-B) inhibitor (rasagiline) in de novo PD [53], but this was followed by a failed RCT for depressive symptoms using this compound [63].

Regarding nonpharmacological approaches, cognitivebehavioral therapy (CBT) has been shown to be efficacious for dPD [64], a positive development given that many dPD patients may prefer psychotherapy, do not respond to pharmacotherapy, or are reluctant to take another medication [65]. A recent meta-analysis concluded that exercise has been shown to have an impact on depressive symptoms in PD [66], but overall the scientific evidence for this is limited.

Finally, for severe, treatment-refractory dPD, electroconvulsive therapy has been shown to be effective, with the added benefit of temporary improvement in parkinsonism [67]. Other stimulation therapies (e.g., repetitive transcranial magnetic stimulation, or rTMS) have not yet shown clear evidence of efficacy for dPD [56]. On average, deep brain stimulation (DBS) surgery and stimulation is associated with improvement in mood, with mixed evidence from two meta-analyses that globus pallidus interna (GPi) lead location is preferred over the subthalamic nucleus (STN) location in terms of mood $[68,69]$; if true, this is perhaps because GPi patients undergo a smaller postoperative decrease in their PD medications [70]. Concerns from case reports and series, and retrospective database reviews [71, 72], that DBS is associated with an increased risk of suicide behaviors has not been supported by RCTs [73].

\section{Anxiety}

Compared with depression, anxiety in $\mathrm{PD}$ has received far less attention to date, which is somewhat surprising given that anxiety can be both mentally and physically disabling at times, particularly when frequent anxiety or panic attacks occur. Up to $40 \%$ of PD patients experience anxiety symptoms or disorders, including generalized anxiety disorder (GAD), anxiety or panic attacks, and social phobia [74-77], and anxiety and depression symptoms are highly comorbid, cooccurring in up to $80 \%$ of patients [78]. Increasing anxiety and discrete anxiety attacks have been associated with nonmotor fluctuations (NMFs), particularly occurring with the onset of "off" periods or at certain times of day (e.g., late afternoon or early evening) [76, 77]. Similar to depression, an increased frequency of anxiety disorders can be observed up to 20 years prior to PD onset $[79,80]$, but other than this finding suggesting a contributing role for disease-related effects on brain monoaminergic nuclei in prodromal PD, little is known about the etiology of anxiety in PD. There is now a PD-specific, validated anxiety rating scale, the Parkinson Anxiety Scale [81].

\section{Management}

There have been no published RCTs focused on anxiety in PD [56], and some [57] but not all [59] antidepressant treatment studies have a reported secondary benefit for anxiety symptoms. Antidepressants, particularly newer medication classes such as SSRIs and SNRIs, should be the first-line medication choice for anxiety in PD, given they all have secondary indications for anxiety disorders and are safe and well-tolerated overall in this population.

For patients who experience anxiety as part of an "off" state (i.e., NMFs), PD medication adjustments using FDAapproved medications for motor fluctuations can be made in an attempt to decrease the duration and severity of these episodes.

However, some patients require treatment with benzodiazepines (e.g., lorazepam or alprazolam during daytime, clonazepam at bedtime) because of the disabling nature of their anxiety symptoms, although this medication class must be used cautiously in PD patients because of its propensity to increase sedation, gait imbalance, and cognitive impairment. In spite of the concerns regarding their use, anxiolytics and sedativehypnotics are common in de novo and early PD [34].

Given possible adverse effects associated with benzodiazepine use in PD, it is important to consider nonpharmacological approaches. In particular, CBT techniques, focusing on maladaptive thoughts and behaviors that can contribute to anxiety symptoms, can be effective for treating situational anxiety and anxiety attacks $[82,83]$.

\section{Psychosis}

Whereas Parkinson disease psychosis (PDP; hallucinations or delusions) was thought to occur in less than $10 \%$ of untreated PD patients and was uncommon prior to the introduction of dopamine replacement therapy (DRT) [84], recent research using a detailed psychiatric interview suggested a high prevalence rate (42\%) for minor hallucinations in de novo, untreated patients [85]. However, these findings require replication, and may have included a subset of patients with cognitive impairment (i.e., dementia with Lewy bodies), or may in some 
cases rather represent the intrusion of rapid eye movement sleep behavior disorder (RBD) visual imagery symptoms into wakefulness [86]. In addition, a prospective study that encompassed currently available PD treatments reported a long-term cumulative prevalence of $60 \%$ [87].

Psychosis is associated with reduced quality of life [88, 89] and worse prognosis [90]. Psychotic symptoms are an independent predictor of increased mortality in PD [91], and are also the single greatest risk factor for nursing home placement [92-94]. Psychosis is associated with increased caregiver burden; when compared with other symptoms in $\mathrm{PD}$, it has been singled out as the most prominent determinant of caregiver distress [95]. The effects on caregivers include deterioration of physical health, increasing depression scores, and strained social life [96]. Related to increased caregiver burden is the finding that PDP is also a major cause of hospitalizations and repeat hospitalizations [97], a significant problem for PD patients, as hospitalization often leads to major disruptions in their PD medication regimen and neurological decline [98].

Although visual hallucinations are most commonly reported in PD, it is now recognized that auditory, tactile, and olfactory hallucinations are also relatively common. [99]. Correlates or risk factors include exposure to PD medications [100], older age [19], and greater cognitive impairment [20], including dementia [101]. In addition, the overwhelming majority of PDP patients also report disturbances of sleep and wakefulness, including RBD [102], and it has been theorized that some hallucinations represent a narcolepsy-like REM sleep disorder during daytime hours, with these hallucinations having particular characteristics (e.g., frequent vision of human figures, faces, or animals, or scenery of great beauty) [86].

Despite the association between medication exposure and PDP, the dosage and duration of antiparkinsonian treatment does not always clearly correlate with psychosis [19, 103], and acute, intravenous, high-dose levodopa challenge does not precipitate hallucinations in PD with pre-existing hallucinations [104], indicating that the etiology of PDP is complex. One proposed mechanism is that chronic DRT may lead to excessive stimulation or hypersensitivity of mesocorticolimbic $\mathrm{D}_{2} / \mathrm{D}_{3}$ receptors [105].

Cholinergic deficits, changes in serotonin $2 \mathrm{~A}\left(5-\mathrm{HT}_{2 \mathrm{~A}}\right)$ receptor occupancy, and serotonergic/dopaminergic imbalance, using a range of imaging modalities and other neural probes, have also been implicated [105-107], particularly in the primary visual system and dorsal/ventral visual association pathways [108-112]. Neurodegeneration of widespread limbic, paralimbic, and neocortical gray matter, including the prefrontal cortex, is associated with PDP [113-115]. Although many genes have been examined for an association with PDP, the results are negative or mixed for all except cholecystokinin $(C C K)[116,117]$.
An IPMDS task force reviewed psychosis rating scales used in PD, and listed four instruments as "recommended" for use in PD as primary outcome measures in clinical trials, including the Neuropsychiatric Inventory (NPI; when a caregiver/informed other is available), Schedule for Assessment of Positive Symptoms (SAPS), Positive and Negative Syndrome Scale (PANSS), and Brief Psychiatric Rating Scale (BPRS), and the Clinical Global Impression Scale (CGIS) as a secondary outcome measure [118]. A relatively recent pivotal RCT [119] used a different instrument, a PD-modified SAPS called the SAPS-PD [120].

\section{Management}

Management of PDP is complex. Observational research suggests that management of comorbid medical conditions and discontinuation or decreasing dosages of nonessential medications may be sufficient for many patients, at least in the short term [121]. PD medications are usually discontinued sequentially and gradually (anticholinergics, MAO-B inhibitors, amantadine, DAs, catechol-O-methyltransferase (COMT) inhibitors, and finally, a reduction in levodopa dosage), although this strategy is expert-recommended as opposed to evidence-based, and the aforementioned ordering is contentious (e.g., discontinuing MAO-B inhibitors, such as rasagiline, before amantadine and DAs) [122].

In PDP, several theoretically promising atypical antipsychotic (AP) medications, such as risperidone [123], olanzapine [124], and aripiprazole [125], either have not been assessed in RCTs or have been tried clinically and found to be associated with adverse events, primarily worsening parkinsonism presumably due to dopamine receptor blocking, which has precluded their routine prescription. In addition, recent research suggests an increased risk of mortality [126] and physical morbidity [127] in PD patients treated with both typical and atypical APs, similar to what has been reported in AD patients.

Among traditional atypical APs, quetiapine is the most commonly used, despite the fact that all RCTs with reasonable sample sizes have been negative or uninterpretable [128-130], and that there is "insufficient evidence" for its efficacy [56]. Three RCTs showed that low-dose clozapine is efficacious for PDP [131-133], yet there is evidence that the drug is underutilized overall in PD [134], likely because of required routine blood monitoring for potential agranulocytosis, as well as adverse events such as sedation, orthostatic hypotension, and sialorrhea.

There is now an FDA-approved treatment specifically for $\mathrm{PDP}$, pimavanserin, which is a selective $5-\mathrm{HT}_{2 \mathrm{~A}}$ receptor inverse agonist without dopamine receptor-blocking properties. Pimavanserin was granted breakthrough therapy designation by the FDA in light of the large unmet need in the treatment of PDP, and was approved on the basis of a single, positive RCT 
[119], with a subsequent partially positive (i.e., positive at week 6 but not at week 12) trial in patients with AD psychosis [135]. Given recent controversy concerning the validity and reliability of the primary outcome measure (the SAPS-PD), the possible delayed response compared with clozapine (2-4 weeks vs. 1 week), and unanswered questions about mortality risk, additional research is needed to confirm the efficacy and more fully evaluate the safety and tolerability of pimavanserin in PDP patients, particularly in patients with comorbid dementia [136, 137], although a secondary analysis of the pivotal PDP study data found that patients with lower Mini-Mental State Examination (MMSE) scores had a more robust response to pimavanserin [138]. Both clozapine and pimavanserin are recommended as "efficacious" for PDP, although pimavanserin is currently available only in the United States.

\section{Impulse control disorders (ICDs) and related behaviors}

This topic has been of increasing importance in PD over the past 15 years, coinciding with the introduction of $\mathrm{D}_{2}$ receptorselective DAs. ICDs were first reported as a sporadic occurrence in case reports or series [139], and then subsequently characterized epidemiologically and phenomenologically in detail. Initial systematic studies showed that ICDs (i.e., most commonly compulsive gambling, buying, sexual behavior, and eating behaviors) occur relatively commonly in treated PD patients [140,141], and more recent studies confirm that ICD rates are not elevated in de novo, untreated patients [142]. As patients may not report such behaviors to a treating physician, either out of embarrassment, because they do not suspect an association with PD treatment, or because they are ambivalent regarding stopping the behavior or causative PD treatment, ICDs still remain generally under-recognized in clinical practice [141], with patient reporting often discrepant from that of the knowledgeable informant [143].

In the largest international, multisite, cross-sectional study done to date, an ICD was identified in $14 \%$ of PD patients, and $29 \%$ of those with an ICD had more than one [144]. A recent national multisite study reported a 5year cumulative ICD incidence rate of $46 \%$, although the study recruited patients from 2009-2013, before significant changes were made in PD medication prescribing [145], and another study found clinically significant ICD symptoms in $36 \%$ of PD patients with dyskinesias [146]. DA treatment is the strongest PD medication correlate [144, 145], but onset of ICDs may not occur until years after DA initiation [147]. Additionally, higher-dose levodopa [144], amantadine [148], and an MAO-B inhibitor [149] have all been associated with ICDs in PD, although to a lesser extent compared with DA treatment. The effects of DAs do not appear unique to PD patients, as a similar association with ICDs has been reported in restless leg syndrome [150, 151], fibromyalgia [152], and prolactinoma or pituitary adenoma [153] treated with a DA.

A personal or familial history of alcoholism or gambling, impulsive or novelty-seeking personality characteristics, young age, male sex, depression and anxiety, and earlier onset of PD have emerged as additional correlates, or potential risk factors, associated with ICDs in PD [140, 144, 154]. A recent study reported that PD patients with comorbid dementia may be at increased risk for developing an ICD in the face of DA treatment [1].

Dopamine dysregulation syndrome (i.e., DDS or compulsive PD medication use) and other compulsive disorders in PD have also been recognized, particularly in countries where high levodopa doses are used [155]. Punding (i.e., repetitive non-goal-directed activity) was reported in $14 \%$ of PD patients on higher levodopa dosages in one study [156], but another larger study of unselected PD patients reported a frequency of $<2 \%$ [157].

A range of cognitive impairments have been reported in PD ICD patients, most commonly executive deficits, including impulsive decision-making and impaired setshifting [158-161]. The dopamine system has been implicated, with both ICD and DDS patients having sensitized $D_{2} / D_{3}$ receptors $[162,163]$, not only in midbrain $D_{2} / D_{3}$ receptors but also in extrastriatal (e.g., anterior cingulate cortex) dopamine receptors [164]; in ICD patients, decreased striatal dopamine transporter (DAT) availability has been reported [165]. Functional imaging studies have reported altered striatal, cingulate, and orbitofrontal activation, and cortico-striatal connectivity, in ICD patients [166-168], particularly when they are in an "on" PD medication state [169].

More recent prospective studies have demonstrated that lower striatal DAT availability may be a risk factor for future ICD development [170], and certain singlenucleotide polymorphisms (e.g., serotonin $2 \mathrm{~A}$ receptor, kappa or mu opioid receptors, and dopamine decarboxylase) previously linked with ICDs in the general population or in PD may also predict incident ICD behaviors with initiation of DRT [171, 172].

Several PD-specific questionnaires and rating scales have been developed for detecting and monitoring ICDs and related behaviors in PD, including the Questionnaire for ImpulsiveCompulsive Disorders in Parkinson Disease (QUIP) [173], Questionnaire for Impulsive-Compulsive Disorders in Parkinson Disease-Rating Scale (QUIP-RS) [174], Ardouin Scale of Behavior in Parkinson Disease [175], and Parkinson Impulse-Control Scale for the Severity Rating of Impulse-Control Behaviors in Parkinson Disease (PICS) [176]. 


\section{Management}

In terms of clinical monitoring, as previously mentioned, the onset of ICDs may not appear until many years after initiation of DA or other PD medication therapy [147, 177], and so ongoing, long-term vigilance is required. ICD behaviors often resolve after discontinuing or decreasing DA treatment, with a concomitant increase in levodopa dosage [178]. However, some patients do not want or cannot tolerate DA discontinuation, and a DA withdrawal syndrome (DAWS) with significant physical and psychological symptoms has been described [179].

The relationship between deep brain stimulation (DBS) and ICDs is complex. STN DBS has been associated with short- and long-term improvement in ICD symptoms [180-182], most notably when a significant decreases in DRT is made postoperatively [183]. However, there is also anecdotal evidence that ICDs may begin or worsen transiently after DBS surgery [184], possibly when DRT doses remain high [185].

A range of psychiatric treatments (e.g., antidepressants and antipsychotics) have been used to treat ICDs in PD, but there is no empirical evidence to support their use in PD patients. A small RCT reported a benefit for an $N$-methyl-D-aspartate (NMDA) antagonist (amantadine) as treatment for pathological gambling in PD [186], but as previously noted, amantadine was associated with ICDs in a large epidemiological study [148]. A RCT using naltrexone, an opioid antagonist FDAapproved for alcohol use disorder, was negative on the primary outcome (Clinical Global Impression-Severity) but positive for change on the rating scale QUIP-RS [187], and there has been a positive CBT study for ICDs in PD [188].

\section{Complications of deep brain stimulation (DBS) surgery}

Over the past 15 years, DBS has increasingly been used as a treatment for PD, and in spite of many studies, its impact on NMS appears to be varied and complex $[189,190]$. In addition to the relationship between DBS and ICDs already discussed, other psychiatric findings after DBS have included both overall improvement and occasionally worsening of depression, anxiety, psychosis, mania, apathy, and emotional lability [189]. In controlled DBS studies, no between-group differences in mood were found after DBS surgery [70, 191], and one study reported improvement in anxiety symptoms with DBS [192]. Interestingly, in one controlled study comparing STN with globus pallidus interna (GPi) DBS, patients who received STN DBS were more likely to experience worsening in both depressive symptoms and processing speed [193], but meta-analyses of RCTs have come to mixed conclusions on this topic $[68,69]$. Clinically, pre- and postoperative psychiatric and cognitive monitoring are important with DBS, especially given reports of postsurgical suicide ideation and completed or attempted suicide [72], although analysis of data from one RCT found no increase in suicide ideation or attempts in the 6-month period after patients were randomized to DBS versus best medical therapy [73].

\section{Nonmotor fluctuations}

Although motor fluctuations (MFs) have long been recognized as a complication of DRT, only more recently has research demonstrated that the majority of patients with MFs also experience NMFs, including anxiety (e.g., anxiety attacks), slowness of thinking, fatigue, and dysphoria, often comorbid with other nonmotor symptoms [194, 195]. Furthermore, NMFs are often the more disabling of these complications [194]. The relationship between motor status and NMFs is complex, as there is not always a correlation between affect and motor state [196, 197], and improvements in mood after levodopa infusion in patients with MFs can precede improvements in motor status [198]. It remains to be seen whether treatments approved on the basis of reducing the severity or duration of MFs, including newly available longer-acting levodopa or levodopa administered via enteral or oral suspension, also lead to improvements in NMF severity or durations.

\section{Other disorders of affect}

\section{Apathy}

Apathy occurs in approximately $40 \%$ of PD patients [199, $200]$ and can occur independently of depression and cognitive impairment, although overlap is common [199, 201]. Studies of apathy in PD have reported associations with executive deficits, verbal memory impairment, and bradyphrenia [199, 202], and with decreased cingulate and inferior frontal gyri volumes [203]. One RCT has shown a benefit for reintroduction of a DA (piribedil) in patients experiencing apathy with DA discontinuation after DBS surgery [204], but there was a negative study for another DA (rotigotine) in a broader PD patient group [205]. Positive RCT results have also been reported for a cholinesterase inhibitor (rivastigmine) for the treatment of PD apathy, not specific to patients with cognitive impairment [206]. In addition, stimulant-like (methylphenidate) and stimulant (amphetamines) medications are used clinically, and the antidepressant bupropion is structurally related to stimulants. 


\section{Pseudobulbar affect}

Pseudobulbar affect (PBA), also called pathological laughing or crying, or affective or emotional lability, can occur in a variety of neurodegenerative diseases and neurological conditions, and prevalence rates of 5-10\% have been reported in PD [207]. Similar to apathy, PBA and depression appear to be overlapping disorders, but clearly distinct, as many patients with PBA do not have clinical depression. PBA has also been reported to occur as part of NMFs and after DBS [208]. Regarding the neuropathophysiology of PBA, a final common pathway appears to be disinhibition of brainstem bulbar nuclei that control the expression of crying and laughing, possibly from impairment in neural pathways connecting the cortex and brainstem [209]. Numerous small-scale studies have found both TCAs and SSRIs to be efficacious in the treatment of PBA, although none included PD patients [210], and studies in multiple sclerosis and amyotrophic lateral sclerosis found a benefit for the FDA-approved combination of dextromethorphan and quinidine [211, 212]. In addition, it is important to educate patients and family members regarding the distinction between PBA and depression.

\section{Global neuropsychiatric symptoms}

Recent neuropsychiatric research focuses on global NPS and advanced statistical techniques to delineate neuropsychiatric profiles in PD, to help account for the substantial comorbidity and interindividual heterogeneity [213]. For instance, in one study that used latent class analysis in a cohort of mild-tomoderate PD patients, three of the four delineated classes (psychiatric, psychiatric-cognitive, cognitive, and intact) experienced significant, but different, patterns of cognitive and psychiatric symptoms and comprised over two-thirds of patients [214]. Another study using factor analysis found that the first and strongest of four factors included cognitive impairment, psychotic symptoms, depression, and Ehlers-Danlos syndrome [215]. Finally, a study using cluster analysis and including both broad nonmotor and motor symptoms identified four clusters: mild, nonmotor-dominant, motor-dominant, and severe. In addition, when including only NMS data, six clusters were identified [216]. This line of research has also established that the burden of global NPS has a significant, detrimental effect on health-related quality of life even in early PD [217].

Several global assessment instruments have recently been developed and tested for clinical use in PD, including the Non-Motor Symptoms Scale (NMSS) [218] and the Scales for Outcomes in Parkinson Disease-Psychiatric Complications (SCOPA-PC) [219]. The Neuropsychiatric Inventory (NPI) [220] is commonly used in PD to document the presence and severity of a range of NPS, and the MDS-
UPDRS [Unified Parkinson's Disease Rating Scale] has an expanded Part I that queries about cognitive impairment, psychosis, depression and anxious mood, apathy, and impulse control disorder behaviors, sleep problems, daytime sleepiness, and fatigue [221]. Finally, the IPMDS has commissioned development and validation of a new global, comprehensive nonmotor rating scale, including NPS, called the MDS-Non-Motor Scale (MDS-NMS), with the primary validation study now completed [222].

\section{Conclusion}

Some overarching themes have emerged over the past 20 years in our understanding of psychiatric complications in PD, which include the following: 1) Prospective, longitudinal studies have demonstrated that the cumulative prevalence of most psychiatric and complications is far higher than earlier cross-sectional studies suggested, with many disorders having a cumulative frequency over $50 \%$, often beginning as early as the prodromal or de novo state [222]. 2) Nonmotor complications are associated overall with excess disability, worse quality of life, poorer outcomes (including morbidity and mortality), and greater caregiver burden. 3) There have been significant advances in the assessment (e.g., questionnaires and rating scales) and diagnosis (i.e., consensus diagnostic criteria) of disorders, which has led to improved clinical management and higher-quality research. 4) Mounting evidence shows that the neural substrate of nonmotor complications in PD is a complex interaction of PD pathology, effects of PD treatments, changes in multiple neurotransmitter systems, impairments in neural circuitry subserving mental functioning, and genetic influences. 5) Core PD treatments, especially DRT and DBS, have a complex and varied effect on psychiatric symptoms. 6) In spite of the advances highlighted above, current treatment options for the range of disorders discussed, although growing, still remain quite limited, with nearly all efficacious drugs developed or first used for similar conditions in non-PD patients. In addition, for some major disorders (e.g., psychosis, cognitive impairment, and depression), there remains evidence for under-recognition and undertreatment $[13,222]$.

High-priority areas for future research in PD include continuing long-term, longitudinal epidemiological research focused on course and predictors of prevalent and incident psychiatric disorders; expanding the use of sophisticated statistical techniques to reconceptualize the classification of neuropsychiatric disorders, to account for the significant interindividual heterogeneity that occurs; improving recognition and diagnosis through continued development and validation of diagnostic criteria and clinically useful assessment tools that are specific to PD; improving our understanding of the neural substrate of neuropsychiatric complications; and conducting 
large-scale clinical trials to determine the efficacy of different interventions for different psychiatric disorders, including the use of disease-modifying agents (when available) to delay or prevent psychiatric complications. Ultimately, reducing the impact of Parkinson disease on patients and families will require improved recognition and development of better therapies for its numerous and clinically significant neuropsychiatric complications.

\section{References}

1. Martinez-Martin P, Wan YM, Ray Chaudhuri K, Schrag AE, Weintraub D. Impulse control and related behaviors in Parkinson's disease with dementia. Eur J Neurol. 2020.

2. Parkinson J. An Essay on the Shaking Palsy. London: Sherwood, Neely and Jones; 18171817.

3. Obeso JA, Stamelou M, Goetz CG, Poewe W, Lang AE, Weintraub D, et al. Past, present, and future of Parkinson's disease: A special essay on the 200th Anniversary of the Shaking Palsy. Mov Disord. 2017;32(9):1264-310.

4. Chaudhuri K, Healy D, Schapira A. Non-motor symptoms of Parkinson's disease: diagnosis and management. Lancet Neurol. 2006;5:235-45.

5. Weintraub D, Burn D. Parkinson's disease: the quintessential neuropsychiatric disorder. Movement Disorders. 2011;26:1022-31.

6. Marras C, Beck JC, Bower JH, Roberts E, Ritz B, Ross GW, et al. Prevalence of Parkinson's disease across North America. NPJ Parkinsons Dis. 2018;4:21.

7. Postuma RB, Berg D, Stern M, Poewe W, Olanow CW, Oertel W, et al. MDS clinical diagnostic criteria for Parkinson's disease. Movement Disorders. 2015;30:1591-601.

8. Allain H, Schuck S, Manduit N. Depression in Parkinson's disease. British Medical Journal. 2000;320:1287-8.

9. Tandberg E, Larsen J, Aarsland D, Cummings J. The occurrence of depression in Parkinson's disease. A community-based study. Archives of Neurology. 1996;53:175-9.

10. Starkstein S, Petracca G, Chemerinski E, Teson A, Sabe L, Merello M, et al. Depression in classic versus akinetic-rigid Parkinson's disease. Movement Disorders. 1998;13:29-33.

11. Reijnders J, Ehrt U, Weber W, Aarsland D, Leentjens A. A systematic review of prevalence studies of depression in Parkinson's disease. Movement Disorders. 2008;23:183-9.

12. Althaus A, Becker O, Spottke A, Dengler R, Schneider F, Kloss $\mathrm{M}$, et al. Frequency and treatment of depressive symptoms in a Parkinson's disease registry. Parkinsonism and Related Disorders. 2008;14:626-32.

13. Shulman L, Taback R, Rabinstein A, Weiner W. Non-recognition of depression and other non-motor symptoms in Parkinson's disease. Parkinsonism and Related Disorders. 2002;8:193-7.

14. Weintraub D, Moberg P, Duda J, Katz I, Stern M. Recognition and treatment of depression in Parkinson's disease. Journal of Geriatric Psychiatry and Neurology. 2003;16:178-83. PMCID: PMC12967062.

15. Starkstein S, Preziosi T, Bolduc P, Robinson R. Depression in Parkinson's disease. Journal of Nervous and Mental Disease. 1990;178:27-31.

16. Leentjens A, Lousberg R, Verhey F. Markers for depression in Parkinson's disease. Acta Psychiatrica Scandinavica. 2002;106: 196-201.
17. Cole S, Woodard J, Juncos J, Kogos J, Youngstrom E, Watts R. Depression and disability in Parkinson's disease. Journal of Neuropsychiatry and Clinical Neurosciences. 1996;8:20-5.

18. Lou J-S, Kearns G, Oken B, Sexton G, Nutt J. Exacerbated physical fatigue and mental fatigue in Parkinson's disease. Movement Disorders. 2001;16:190-6.

19. Aarsland D, Larsen J, Cummings J, Laake K. Prevalence and clinical correlates of psychotic symptoms in Parkinson disease: a community-based study. Archives of Neurology. 1999;56:595601.

20. Marsh L, Williams J, Rocco M, Grill S, Munro C, Dawson T. Psychiatric comorbidities in patients with Parkinson disease and psychosis. Neurology. 2004;63:293-300.

21. Caap-Ahlgren M, Dehlin O. Insomnia and depressive symptoms in patients with Parkinson's disease. Relationship to health-related quality of life. An interview of patients living at home. Archives of Gerontology and Geriatrics. 2001;32:23-33.

22. Leentjens A. Depression in Parkinson's disease: conceptual issues and clinical challenges. Journal of Geriatric Psychiatry and Neurology. 2004;17:120-6.

23. Leentjens AF, Moonen AJ, Dujardin K, Marsh L, MartinezMartin P, Richard IH, et al. Modeling depression in Parkinson disease: disease-specific and nonspecific risk factors. Neurology. 2013;81(12):1036-43.

24. Leentjens A, Marinus J, Van Hilten J, Lousberg R, Verhey F. The contribution of somatic symptoms to the diagnosis of depression in Parkinson's disease: a discriminant analytic approach. Journal of Neuropsychiatry and Clinical Neurosciences. 2003;15:74-7.

25. Stenager E, Wermuth L, Stenager E, Boldsen J. Suicide in patients with Parkinson's disease: an epidemiological study. Acta Psychiatrica Scandinavica. 1994;90:70-2.

26. Myslobodsky M, Lalonde F, Hicks L. Are patients with Parkinson's disease suicidal? Journal of Geriatric Psychiatry and Neurology. 2001;14:120-4.

27. Menza M, Golbe L, Cody R, Forman N. Dopamine-related personality traits in Parkinson's disease. Neurology. 1993;43:505-8.

28. Santangelo G, Garramone F, Baiano C, D'Iorio A, Piscopo F, Raimo S, et al. Personality and Parkinson's disease: A meta-analysis. Parkinsonism Relat Disord. 2018;49:67-74.

29. Nazem S, Siderowf A, Duda J, Brown G, Ten Have T, Stern M, et al. Suicidal and death ideation in Parkinson's disease. Movement Disorders. 2008;10:1573-9. PMCID: PMD18618660.

30. Shepard MD, Perepezko K, Broen MPG, Hinkle JT, Butala A, Mills KA, et al. Suicide in Parkinson's disease. J Neurol Neurosurg Psychiatry. 2019.

31. Erlangsen A, Stenager E, Conwell Y, Andersen PK, Hawton K, Benros ME, et al. Association between neurological disorders and death by suicide in Denmark. JAMA. 2020;323(5):444-54.

32. Menza M, Mark M. Parkinson's disease and depression: the relationship to disability and personality. Journal of Neuropsychiatry and Clinical Neurosciences. 1994;6:165-9.

33. Tandberg E, Larsen J, Aarsland D, Laake K, Cummings J. Risk factors for depression in Parkinson disease. Archives of Neurology. 1997;54:625-30.

34. Weintraub D, Caspell-Garcia C, Simuni T, Cho HR, Coffey CS, Aarsland D, et al. Neuropsychiatric symptoms and cognitive abilities over the initial quinquennium of Parkinson disease. Ann Clin Transl Neurol. 2020

35. Gotham A-M, Brown R, Marsden C. Depression in Parkinson's disease: a quantitative and qualitative analysis. Journal of Neurology, Neurosurgery and Psychiatry. 1986;49:381-9.

36. Fang G, Xu Q, Park Y, Huang X, Hollenbeck A, Blair A, et al. Depression and subsequent risk of Parkinson's disease in the NIHAARP Diet and Health Study. Movement Disorders. 2010;25: 1157-62. 
37. Alonso A, Rodriguez L, Logroscino G, Hernan M. Use of antidepressants and the risk of Parkinson's disease: a prospective study. Journal of Neurology, Neurosurgery and Psychiatry. 2009;80: 671-5.

38. Schrag A, Horsfall L, Walters K, Noyce A, Petersen I. Prediagnostic presentations of Parkinson's disease in primary care: a case-control study. Lancet Neurol. 2014;14:57-64.

39. Nilsson F, Kessing L, Bolwig T. Increased risk for developing Parkinson's disease for patients with major affective disorder: a register study. Acta Psychiatrica Scandinavica. 2001;104:380-6.

40. Mentis M, McIntosh A, Perrine K, Dhawan V, Berlin B, Feigin A, et al. Relationships among the metabolic patterns that correlate with mnemonic, visuospatial, and mood symptoms in Parkinson's disease. American Journal of Psychiatry. 2002;159: 746-54.

41. Feldmann A, Illes Z, Kosztolanyi P, Iles E, Mike A, Kover F, et al. Morphometric changes of gray matter in Parkinson's disease with depression: a voxel-based morphometry study. Movement Disorders. 2008;23:42-6.

42. Cardoso E, Maia F, Fregni F, Myczkowski M, Melo L, Sato J, et al. Depression in Parkinson's disease: convergence from voxelbased morphometry and functional magnetic resonance imaging in the limbic thalamus. NeuroImage. 2009;47:467-72.

43. Walter U, Skoloukik D, Berg D. Transcranial sonography findings related to non-motor features of Parkinson's disease. Journal of Neurological Science. 2010;289:123-7.

44. Mayberg H. Modulating dysfunctional limbic-cortical circuits in depression: towards development of brain-based algorithms for diagnosis and optimised treatment. British Medical Bulletin. 2003;65:193-207.

45. Murai T, Muller U, Werheid K, Sorger D, Reuter M, Becker T, et al. In vivo evidence for differential association of striatal dopamine and midbrain serotonin systems with neuropsychiatric symptoms in Parkinson's disease. Journal of Neuropsychiatry and Clinical Neurosciences. 2001;13:222-8.

46. Hesse S, Meyer P, Strecker K, Barthel H, Wegner F, Oehlwein C, et al. Monoamine transporter availability in Parkinson's disease patients with or without depression. European Journal of Nuclear Medicine and Molecular Imaging. 2009;36:428-35.

47. Weintraub D, Newberg A, Cary M, Siderowf A, Moberg P, Kleiner-Fisman G, et al. Striatal dopamine transporter imaging correlates with anxiety and depression symptoms in Parkinson's disease. Journal of Nuclear Medicine. 2005;46:227-32. PMCID: PMC15695780.

48. Felicio A, Moriyama T, Godeiro-Junior C, Shih M, Hoexter M, Borges V, et al. Higher dopamine transporter density in Parkinson's disease patients with depression. Psychopharmacology. 2010;211:27-31.

49. Zheng J, Yang X, Zhao Q, Tian S, Huang H, Chen Y, et al. Association between gene polymorphism and depression in Parkinson's disease: A case-control study. Journal of Neurological Science. 2017;375:231-4

50. Schrag A, Barone P, Brown R, Leentjens A, McDonald W, Starkstein S, et al. Depression rating scales in Parkinson's disease: critique and recommendations. Movement Disorders. 2007;22: 1077-92. PMCID: PMC17394234.

51. Marsh L, McDonald W, Cummings J, Ravina B, Disease NNWGoDaPs. Provisional diagnostic criteria for depression in Parkinson's disease: report of an NINDS/NIMH work group. Movement Disorders. 2006;21:148-58.

52. Olin J, Schneider L, Katz I, Meyers B, Alexopoulos GS, Breitner $\mathrm{J}$, et al. Provisional diagnostic criteria for depression of Alzheimer disease. American Journal of Geriatric Psychiatry. 2002;10:125-8.

53. Smith KM, Eyal E, Weintraub D. Combined rasagiline and antidepressant use in Parkinson disease in the ADAGIO study: effects on nonmotor symptoms and tolerability. JAMA Neurology. 2015;72(1):88-95.

54. Richard I, Kurlan R, Group PS. A survey of antidepressant use in Parkinson's disease. Neurology. 1997;49:1168-70.

55. Caspell-Garcia C, Simuni T, Tosun-Turgut D, Wu IW, Zhang Y, Nalls M, et al. Multiple modality biomarker prediction of cognitive impairment in prospectively followed de novo Parkinson disease. PLoS One. 2017;12(5):e0175674.

56. Seppi K, Ray Chaudhuri K, Coelho M, Fox SH, Katzenschlager $\mathrm{R}$, Perez Lloret S, et al. Update on treatments for nonmotor symptoms of Parkinson's disease-an evidence-based medicine review. Mov Disord. 2019;34:180-98.

57. Menza M, Dobkin R, Marin H, Mark M, Gara M, Buyske S, et al. A controlled trial of antidepressants in patients with Parkinson's disease and depression. Neurology. 2009;72:886-92.

58. Devos D, Dujardin K, Poirot I, Moreau C, Cottencin O, Thomas P, et al. Comparison of desipramine and citalopram treatments for depression in Parkinson's disease: a double-blind, randomized, placebo-controlled study. Movement Disorders. 2008;23:850-7.

59. Richard I, McDermott M, Kurlan R, Lyness J, Como P, Pearson $\mathrm{N}$, et al. A randomized, double-blind, placebo-controlled trial of antidepressants in Parkinson's disease. Neurology. 2012;78:122936.

60. Weintraub D, Mavandadi S, Mamikonyan E, Siderowf A, Duda J, Hurtig H, et al. Atomoxetine for depression and other neuropsychiatric symptoms in Parkinson's disease. Neurology. 2010;75: 448-55.

61. Barone P, Poewe W, Albrecht S, Debieuvre C, Massey D, Rascol $\mathrm{O}$, et al. Pramipexole for the treatment of depressive symptoms in patients with Parkinson's disease: a randomised, double-blind, placebo-controlled trial. Lancet Neurol. 2010;9:573-80.

62. Chung SJ, Asgharnejad M, Bauer L, Ramirez F, Jeon B. Evaluation of rotigotine transdermal patch for the treatment of depressive symptoms in patients with Parkinson's disease. Expert Opin Pharmacother. 2016;17(11):1453-61.

63. Barone P, Santangelo G, Morgante L, Onofrj M, Meco G, Abbruzzese $\mathrm{G}$, et al. A randomized clinical trial to evaluate the effects of rasagiline on depressive symptoms in non-demented Parkinson's disease patients. Eur J Neurol. 2015;22(8):1184-91.

64. Dobkin R, Menza M, Allen L, Gara M, Mark M, Tiu J, et al. Cognitive-behavioral therapy for depression in Parkinson's disease: A randomized, controlled trial. American Journal of Psychiatry. 2011;168:1066-74.

65. Oehlberg K, Barg F, Weintraub D, Brown G, Taraborelli D, Katz I, et al. How depressed Parkinson's disease patients view the etiology and treatment of depression. Journal of Geriatric Psychiatry and Neurology. 2008;21:123-32. PMCID: PMC18474721.

66. Wu PL, Lee M, Huang TT. Effectiveness of physical activity on patients with depression and Parkinson's disease: A systematic review. PLoS One. 2017;12(7):e0181515.

67. Popeo D, Kellner CH. ECT for Parkinson's disease. Med Hypotheses. 2009;73(4):468-9.

68. Sako W, Miyazaki Y, Izumi Y, Kaji R. Which target is best for patients with Parkinson's disease? A meta-analysis of pallidal and subthalamic stimulation. J Neurol Neurosurg Psychiatry. 2014;85(9):982-6.

69. Wang JW, Zhang YQ, Zhang XH, Wang YP, Li JP, Li YJ. Cognitive and psychiatric effects of STN versus GPi deep brain stimulation in Parkinson's disease: a meta-analysis of randomized controlled trials. PLoS One. 2016;11(6): 0156721.

70. Weaver F, Follett K, Stern M, Hur K, Harris C, Marks W, et al. Bilateral deep brain stimulation vs best medical therapy for patients with advanced Parkinson disease: a randomized clinical trial. JAMA. 2009;301:63-73.

71. Giannini G, Francois M, Lhommee E, Polosan M, Schmitt E, Fraix V, et al. Suicide and suicide attempts after subthalamic 
nucleus stimulation in Parkinson disease. Neurology. 2019;93(1): e97-e105.

72. Voon V, Krack P, Lang A, Lozano A, Dujardin K, Schüpbach M, et al. A multicentre study on suicide outcomes following subthalamic stimulation for Parkinson's disease. Brain. 2008;131:27208 .

73. Weintraub D, Duda J, Carlson K, Luo P, Sagher O, Stern M, et al. Suicide ideation and behaviors after STN and GPi DBS surgery for Parkinson's disease: results from a randomized, controlled trial. Journal of Neurology, Neurosurgery and Psychiatry. 2013;84: 1113-8.

74. Richard I, Schiffer R, Kurlan R. Anxiety and Parkinson's disease. Journal of Neuropsychiatry and Clinical Neurosciences. 1996;8: 383-92.

75. Kummer A, Cardoso F, Teixeira A. Frequency of social phobia and psychometric properties of the Liebowitz social anxiety scale in Parkinson's disease. Movement Disorders. 2008;23:1739-43.

76. Pontone G, Williams J, Anderson K, Chase G, Goldstein S, Grill $\mathrm{S}$, et al. Prevalence of anxiety disorders and anxiety subtypes in patients with Parkinson's disease. Movement Disorders. 2009;24: 1333-8.

77. Dissanayaka N, Sellbach A, Matheson S, O'Sullivan J, Silburn P, Byrne G, et al. Anxiety disorders in Parkinson's disease: prevalence and risk factors. Movement Disorders. 2010;25:838-45.

78. Menza M, Robertson-Hoffman D, Bonapace A. Parkinson's disease and anxiety: comorbidity with depression. Biological Psychiatry. 1993;34:465-70.

79. Gonera E, van't Hof M, Berger H, van Weel C, Horstink M. Symptoms and duration of the prodromal phase in Parkinson's disease. Movement Disorders. 1997;12:871-6.

80. Shiba M, Bower J, Maraganore D, McDonnell S, Peterson B, Ahlskog J, et al. Anxiety disorders and depressive disorders preceding Parkinson's Disease: a case-control study. Movement Disorders. 2000;15:669-77.

81. Leentjens AF, Dujardin K, Pontone GM, Starkstein SE, Weintraub D, Martinez-Martin P. The Parkinson Anxiety Scale (PAS): development and validation of a new anxiety scale. Mov Disord. 2014;29(8):1035-43.

82. Reynolds GO, Saint-Hilaire M, Thomas CA, Barlow DH, CroninGolomb A. Cognitive-behavioral therapy for anxiety in Parkinson's disease. Behav Modif. 2019:145445519838828.

83. Armento ME, Stanley MA, Marsh L, Kunik ME, York MK, Bush AL, et al. Cognitive behavioral therapy for depression and anxiety in Parkinson's disease: a clinical review. J Parkinsons Dis. 2012;2(2):135-51.

84. Fénelon G, Goetz C, Karenberg A. Hallucinations in Parkinson disease in the prelevodopa era. Neurology. 2006;66:93-8.

85. Pagonabarraga J, Martinez-Horta S, Fernandez de Bobadilla R, Perez J, Ribosa-Nogue R, Marin J, et al. Minor hallucinations occur in drug-naive Parkinson's disease patients, even from the premotor phase. Movement Disorders. 2016;31:45-52.

86. Arnulf I, Bonnet A-M, Damier P, Bejjani B-P, Seilhean D, Derenne J-P, et al. Hallucinations, REM sleep, and Parkinson's disease: a medical hypothesis. Neurology. 2000;55:281-8.

87. Forsaa E, Larsen J, Wentzel-Larsen T, Goetz C, Stebbins G, Aarsland D, et al. A 12-year population-based study of psychosis in Parkinson disease. Archives of Neurology. 2010;67:996-1001.

88. McKinlay A, Grace R, Dalrymple-Alford J, Anderson T, Fink J, Roger D. A profile of neuropsychiatric problems and their relationship to quality of life for Parkinson's disease patients without dementia. Parkinsonism and Related Disorders. 2008;14:37-42.

89. Alvarado-Bolanos A, Cervantes-Arriaga A, Rodriguez-Violante M, Llorens-Arenas R, Calderon-Fajardo H, Millan-Cepeda R, et al. Impact of neuropsychiatric symptoms on the quality of life of subjects with Parkinson's disease. J Parkinsons Dis. 2015;5(3): 541-8.
90. Friedman JH. Parkinson disease psychosis: Update. Behav Neurol. 2013;27(4):469-77.

91. Forsaa E, Larsen J, Wentzel-Larsen T, Alves G. What predicts mortality in Parkinson disease? A prospective population-based long-term study. Neurology. 2010;75:1270-6.

92. Aarsland D, Larsen J, Tandberg E, al e. Predictors of nursing home placement in Parkinson's Disease: a population-based, prospective study. Journal of the American Geriatrics Society. 2000;48:938-42.

93. Goetz C, Stebbins G. Risk factors for nursing home placement in advanced Parkinson's disease. Neurology. 1993;43:2227-9.

94. Factor S, Feustel P, Freidman J, Comella C, Goetz C, Kurlan R, et al. Longitudinal outcome of Parkinson's disease patients with psychosis. Neurology. 2003;60:1756-61.

95. Rodriguez-Violante M, Camacho-Ordonez A, Cervantes-Arriaga A, Gonzalez-Latapi P, Velazquez-Osuna S. Factors associated with the quality of life of subjects with Parkinson's disease and burden on their caregivers. Neurologia. 2015;30(5):257-63.

96. Schrag A, Hovris A, Morley D, Quinn N, Jahanshahi M. Caregiver-burden in Parkinson's disease is closely associated with psychiatric symptoms, falls, and disability. Parkinsonism and Related Disorders. 2006;12:35-41.

97. Klein C, Prokhorov T, Miniovitz A, Dobronevsky E, Rabey JM. Admission of Parkinsonian patients to a neurological ward in a community hospital. J Neural Transm (Vienna). 2009;116(11): 1509-12.

98. Gerlach $\mathrm{OH}$, Winogrodzka A, Weber WE. Clinical problems in the hospitalized Parkinson's disease patient: systematic review. Mov Disord. 2011;26(2):197-208.

99. Fenelon G, Soulas T, Zenasni F, de Langavant L. The changing face of Parkinson's disease-associated psychosis: a cross-sectional study based on the new NINDS-NIMH criteria. Movement Disorders. 2010;25:763-6.

100. Henderson M, Mellers J. Psychosis in Parkinson's disease: 'between a rock and a hard place'. International Review of Psychiatry. 2000;12:319-34.

101. Aarsland D, Cummings J, Larsen J. Neuropsychiatric differences between Parkinson's disease with dementia and Alzheimer's disease. International Journal of Geriatric Psychiatry. 2001;16:18491.

102. Pacchetti C, Manni R, Zangaglia R, Mancini F, Marchioni E, Tassorelli C, et al. Relationship between hallucinatons, delusions, and rapid eye movement sleep behavior disorder in Parkinson's disease. Movement Disorders. 2005;20:1439-48.

103. Sanchez-Ramos J, Ortoll R, Paulson G. Visual hallucinations associated with Parkinson disease. Archives of Neurology. 1996;53: 1265-8.

104. Goetz CG, Pappert EJ, Blasucci LM, Stebbins GT, Ling ZD, Nora MV, et al. Intravenous levodopa in hallucinating Parkinson's disease patients: high-dose challenge does not precipitate hallucinations. Neurology. 1998;50(2):515-7.

105. Wolters E. Dopaminomimetic psychosis in Parkinson's disease patients: diagnosis and treatment. Neurology. 1999;52(Suppl 3): S10-S3.

106. Wolters E. Intrinsic and extrinsic psychosis in Parkinson's disease. Journal of Neurology. 2001;248 (Suppl 3):22-7.

107. Manganelli F, Vitale C, Santangelo G, Pisciotta C, Iodice R, Cozzolino A, et al. Functional involvement of central cholinergic circuits and visual hallucinations in Parkinson's disease. Brain. 2009; 132:2350-5.

108. Huot P, Johnston TH, Darr T, Hazrati LN, Visanji NP, Pires D, et al. Increased 5-HT2A receptors in the temporal cortex of parkinsonian patients with visual hallucinations. Mov Disord. 2010;25(10):1399-408. 
109. Ballanger B, Strafella A, van Eimeren T, Zurowski M, Rusjan P, Houle S, et al. Serotonin 2A receptors and visual hallucinations in Parkinson disease. Archives of Neurology. 2010;67:416-21.

110. Kurita A, Murakami M, Takagi S, Matsushima M, Suzuki M. Visual hallucinations and altered visual information processing in Parkinson disease and dementia with Lewy bodies. Movement Disorders. 2010;25:167-71.

111. Ramirez-Ruiz B, Martí M, Tolosa E, Falcón C, Bargalló N, Valldeoriola $\mathrm{F}$, et al. Brain response to complex visual stimuli in Parkinson's patients with hallucinations: a functional magnetic resonance imaging study. Movement Disorders. 2008;23:233543.

112. Boecker H, Ceballos-Baumann A, Volk D, Conrad B, Forstl H, Haussermann P. Metabolic alterations in patients with Parkinson disease and visual hallucinations. Archives of Neurology. 2007;64:984-8

113. Sanchez-Castaneda C, Rene R, Ramirez-Ruiz B, Campdelacreu J, Gascon J, Falcon C, et al. Frontal and associative visual areas related to visual hallucinations in dementia with Lewy bodies and Parkinson's disease with dementia. Movement Disorders. 2010;25:615-22.

114. Ibarretxe-Bilbao N, Ramirez-Ruiz B, Junque C, Marti M, Valldeoriola F, Bargallo N, et al. Differential progression of brain atrophy in Parkinson's disease with and without visual hallucinations. Journal of Neurology, Neurosurgery and Psychiatry. 2010;81:650-7.

115. Goldman J, Stebbins G, Dinh V, Bernard B, Merkitch D, deToledo-Morrell L, et al. Visuoperceptive region atrophy independent of cognitive status in patients with Parkinson's disease with hallucinations. Brain. 2014;137:849-59.

116. Goldman J, Goetz C, Berry-Kravis E, Leurgans S, Zhou L. Genetic polymorphisms in Parkinson disease subjects with and without hallucinations: an analysis of the cholecystokinin system. Archives of Neurology. 2004;61:1280-4.

117. Lenka A, Arumugham SS, Christopher R, Pal PK. Genetic substrates of psychosis in patients with Parkinson's disease: A critical review. J Neurol Sci. 2016;364:33-41.

118. Fernandez H, Aarsland D, Fénelon G, Friedman J, Marsh L, Tröster A, et al. Scales to assess psychosis in Parkinson's disease: critique and recommendations. Movement Disorders. 2008;23: 484-500.

119. Cummings $\mathrm{J}$, Isaacson $\mathrm{S}$, Mills R, Williams H, Chi-Burris K, Corbett A, et al. Pimavanserin for patients with Parkinson's disease psychosis: a randomised, placebo-controlled phase 3 trial. Lancet. 2014;383:533-40.

120. Voss T, Bahr D, Cummings J, Mills R, Ravina B, Williams H. Performance of a shortened Scale for Assessment of Positive Symptoms for Parkinson's disease psychosis. Parkinsonism Relat Disord. 2013;19(3):295-9.

121. Thomsen T, Panisset M, Suchowersky O, Goodridge A, Mendis T, Lang A. Impact of standard of care for psychosis in Parkinson disease. Journal of Neurology, Neurosurgery and Psychiatry. 2008;79:1413-5.

122. Olanow C, Stern M, Sethi K. The scientific and clinical basis of the treatment of Parkinson disease (2009). Neurology. 2009;72 (Supplement 4):S1-S136.

123. Mohr E, Mendis T, Hildebrand K, De Deyn PP. Risperidone in the treatment of dopamine-induced psychosis in Parkinson's disease: an open pilot trial. Mov Disord. 2000;15(6):1230-7.

124. Nichols MJ, Hartlein JM, Eicken MG, Racette BA, Black KJ. A fixed-dose randomized controlled trial of olanzapine for psychosis in Parkinson disease. F1000Res. 2013;2:150.

125. Fernandez H, Trieschmann M, Friedman J. Aripiprazole for druginduced psyhcosis in Parkinson's disease: preliminary experience. Clinical Neuropharmacology. 2004;27:4-5.
126. Weintraub D, Chiang C, Kim HM, Wilkinson J, Marras C, Stanislawski B, et al. Association of antipsychotic use with mortality risk in patients with Parkinson disease. JAMA Neurol. 2016;73(5):535-41.

127. Weintraub D, Chiang C, Kim HM, Wilkinson J, Marras C, Stanislawski B, et al. Antipsychotic use and physical morbidity in Parkinson disease. Am J Geriatr Psychiatry. 2017;25:697-705.

128. Ondo W, Tintner R, Voung K, et al. Double-blind, placebo-controlled, unforced titration parallel trial of quetiapine for dopaminergic-induced hallucinations in Parkinson's disease. Movement Disorders. 2005;20:958-63.

129. Rabey J, Prokhorov T, Miniovitz A, Dobronevsky E, Klein C. Effect of quetiapine in psychotic Parkinson's disease patients: a double-blind labeled study of 3 months' duration. Movement Disorders. 2007;22:313-8.

130. Shotbolt P, Samuel M, Fox C, David A. A randomized controlled trial of quetiapine for psychosis in Parkinson's disease. Neuropsychiatric Disease and Treatment. 2009;5:327-32.

131. Group TPS. Low-dose clozapine for the treatment of drug-induced psychosis in Parkinson's disease. New England Journal of Medicine. 1999;340:757-63.

132. Group TFCPS. Clozapine in drug-induced psychosis in Parkinson's disease. The Lancet. 1999;353:2041-2.

133. Pollak P, Tison F, Rascol O, et al. Clozapine in drug induced psychosis in Parkinson's disease: a randomised, placebo controlled study with open follow up. Journal of Neurology, Neurosurgery and Psychiatry. 2004;75:689-95.

134. Weintraub D, Chen P, Ignacio R, Mamikonyan E, Kales H. Patterns and trends in antipsychotic prescribing for Parkinson disease psychosis. Archives of Neurology. 2011;68:899-904.

135. Ballard C, Banister C, Khan Z, Cummings J, Demos G, Coate B, et al. Evaluation of the safety, tolerability, and efficacy of pimavanserin versus placebo in patients with Alzheimer's disease psychosis: a phase 2, randomised, placebo-controlled, doubleblind study. Lancet Neurol. 2018;17(3):213-22.

136. Schubmehl S, Sussman J. Perspective on pimavanserin and the SAPS-PD: novel scale development as a means to FDA approval. American Journal of Geriatric Psychiatry. 2018;26:1007-11.

137. The Lancet Neurology. Difficult choices in treating Parkinson's disease psychosis. Lancet Neurol. 2018;17(7):569.

138. Espay AJ, Guskey MT, Norton JC, Coate B, Vizcarra JA, Ballard $\mathrm{C}$, et al. Pimavanserin for Parkinson's disease psychosis: effects stratified by baseline cognition and use of cognitive-enhancing medications. Mov Disord. 2018;33(11):1769-76.

139. Driver-Dunckley E, Samanta J, Stacy M. Pathological gambling associated with dopamine agonist therapy in Parkinson's disease. Neurology. 2003;61:422-3.

140. Voon V, Fox S. Medication-related impulse control and repetitive behaviors in Parkinson disease. Archives of Neurology. 2007;64: 1089-96.

141. Weintraub D, Siderowf A, Potenza M, Goveas J, Morales K, Duda $\mathrm{J}$, et al. Association of dopamine agonist use with impulse control disorders in Parkinson disease. Archives of Neurology. 2006;63: 969-73.

142. Weintraub D, Papay K, Siderowf A, Parkinson's Progression Markers Initiative. Screening for impulse control disorder symptoms in patients with de novo Parkinson disease: a case-control study. Neurology. 2013;80:176-80.

143. Papay K, Mamikonyan E, Siderowf A, Duda J, Lyons K, Pahwa $\mathrm{R}$, et al. Patient versus informant reporting of ICD symptoms in Parkinson's disease using the QUIP: Validity and variability. Parkinsonism and Related Disorders. 2011;17:153-5.

144. Weintraub D, Koester J, Potenza M, Siderowf A, Stacy M, Voon $\mathrm{V}$, et al. Impulse control disorders in Parkinson disease: A crosssectional study of 3090 patients. Archives of Neurology. 2010;67: $589-95$. 
145. Corvol JC, Artaud F, Cormier-Dequaire F, Rascol O, Durif F, Derkinderen $\mathrm{P}$, et al. Longitudinal analysis of impulse control disorders in Parkinson disease. Neurology. 2018;91:e189-e201.

146. Biundo R, Weis L, Abbruzzese G, Calandra-Buonaura G, Cortelli $\mathrm{P}$, Jori $\mathrm{MC}$, et al. Impulse control disorders in advanced Parkinson's disease with dyskinesia: The ALTHEA study. Mov Disord. 2017;32:1557-65.

147. Antonini A, Chaudhuri KR, Boroojerdi B, Asgharnejad M, Bauer L, Grieger F, et al. Impulse control disorder related behaviours during long-term rotigotine treatment: a post hoc analysis. Eur J Neurol. 2016;23(10):1556-65.

148. Weintraub D, Sohr M, Potenza M, Siegal A, Stacy M, Voon V, et al. Amantadine use associated with impulse control disorders in Parkinson disease in cross-sectional study. Annals of Neurology. 2010;68:963-8.

149. Garcia-Ruiz P, Castrillo J, Alonso-Canovas A, Barcenas A, Vela $\mathrm{L}$, Alonso $\mathrm{P}$, et al. Impulse control disorders in patients with Parkinson's disease under dopamine agonist therapy: a multicentre study. Journal of Neurology, Neurosurgery and Psychiatry. 2014;85:840-4

150. Ondo W, Lai D. Predictors of impulsivity and reward seeking behavior with dopamine agonists. Parkinsonism and Related Disorders. 2008;14:28-32.

151. Cornelius J, Tippmann-Peikert M, Slocumb N, Frerichs C, Silber M. Impulse control disorders with the use of dopaminergic agents in restless legs syndrome: a case-control study. Sleep. 2010;33:817.

152. Holman A. Impulse control disorder behaviors associated with pramipexole used to treat fibromyalgia. Journal of Gambling Studies. 2009;25:425-31

153. Bancos I, Nannenga MR, Bostwick JM, Silber MH, Erickson D, Nippoldt TB. Impulse control disorders in patients with dopamine agonist-treated prolactinomas and nonfunctioning pituitary adenomas: a case-control study. Clin Endocrinol (Oxf). 2014;80(6):8638 .

154. Voon V, Sohr M, Lang A, Potenza M, Siderowf A, Whetteckey J, et al. Impulse control disorders in Parkinson disease: a multicenter case-control study. Annals of Neurology. 2011;69:986-96.

155. Giovannoni G, O'Sullivan J, Turner K, Manson A, Lees A. Hedonistic homeostatic dysregulation in patients with Parkinson's disease on dopamine replacement therapies. Journal of Neurology, Neurosurgery and Psychiatry. 2000;68:423-8.

156. Evans A, Katzenschlager R, Paviour D, O'Sullivan J, Appel S, Lawrence A, et al. Punding in Parkinson's disease: its relation to the dopamine dysregulation syndrome. Movement Disorders. 2004;19:397-405.

157. Miyasaki J, Hassan K, Lang A, Voon V. Punding prevalence in Parkinson's disease. Movement Disorders. 2007;22:1179-81.

158. Voon V, Reynolds B, Brezing C, Gallea C, Skaljic M, Ekanayake $\mathrm{V}$, et al. Impulsive choice and response in dopamine agonistrelated impulse control behaviors. Psychopharmacology. 2010;207:645-59.

159. Housden C, O'Sullivan S, Joyce E, Lees A, Roiser J. Intact reward learning but elevated delay discounting in Parkinson's disease patients with impulsive-compulsive spectrum behaviors. Neuropsychopharmacology. 2010;35:2155-64.

160. Santangelo G, Vitale C, Trojano L, Verde F, Grossi D, Barone P. Cognitive dysfunctions and pathological gambling in patients with Parkinson's disease. Movement Disorders. 2009;24:899-905.

161. Martini A, Dal Lago D, Edelstyn NMJ, Grange JA, Tamburin S. Impulse control disorder in Parkinson's disease: a eta-analysis of cognitive, affective, and motivational correlates. Front Neurol. 2018;9:654

162. Evans A, Pavese N, Lawrence A, Tai Y, Appel S, Doder M, et al. Compulsive drug use linked to sensitized ventral striatal dopamine transmission. Annals of Neurology. 2006;59:852-8.
163. Steeves T, Miyasaki J, Zurowski M, Lang A, Pellecchia G, van Eimeren T, et al. Increased striatal dopamine release in parkinsonian patients with pathological gambling: a ${ }^{11} \mathrm{C}$ raclopride PET study. Brain. 2009;132:1376-85.

164. Ray N, Miyasaki J, Zurowski M, Ko J, Cho S, Pellecchia G, et al. Extrastriatal dopaminergic abnormalities of DA homeostasis in Parkinson's patients with medication-induced pathological gambling: A [11C] FLB-457 and PET study. Neurobiology of Disease. 2012;48:519-25.

165. Cilia R, Ko J, Cho S, van Eimeren T, Marotta G, Pellecchia G, et al. Reduced dopamine transporter density in the ventral striatum of patients with Parkinson's disease and pathological gambling. Neurobiology of Disease. 2010;39:98-104.

166. Voon V, Pessiglione M, Brezing C, Gallea C, Fernandez H, Dolan $\mathrm{R}$, et al. Mechanisms underlying dopamine-mediated reward bias in compulsive behaviors. Neuron. 2010;65:135-42.

167. Rao H, Mamikonyan E, Detre J, Siderowf A, Stern M, Potenza M, et al. Decreased ventral striatal activity with impulse control disorders in Parkinson's disease. Movement Disorders. 2010;25: 1660-9.

168. Claassen DO, Stark AJ, Spears CA, Petersen KJ, van Wouwe NC, Kessler RM, et al. Mesocorticolimbic hemodynamic response in Parkinson's disease patients with compulsive behaviors. Mov Disord. 2017;32:1574-83.

169. Politis M, Loane C, Wu K, O'Sullivan S, Woodhead Z, Kiferle L, et al. Neural response to visual sexual cues in dopamine treatmentlinked hypersexuality in Parkinson's disease. Brain. 2013;136: 400-11.

170. Smith KM, Xie SX, Weintraub D. Incident impulse control disorder symptoms and dopamine transporter imaging in Parkinson disease. J Neurol Neurosurg Psychiatry. 2016;87(8):864-70.

171. Kraemmer J, Smith K, Weintraub D, Guillemot V, Nalls MA, Cormier-Dequaire $\mathrm{F}$, et al. Clinical-genetic model predicts incident impulse control disorders in Parkinson's disease. J Neurol Neurosurg Psychiatry. 2016;87(10):1106-11.

172. Cormier-Dequaire F, Bekadar S, Anheim M, Lebbah S, Pelissolo A, Krack P, et al. Suggestive association between OPRM1 and impulse control disorders in Parkinson's disease. Mov Disord. 2018;33(12):1878-86

173. Weintraub D, Stewart S, Shea J, Lyons K, Pahwa R, DriverDunckley E, et al. Validation of the Questionnaire for Impulsive-Compulsive Behaviors in Parkinson's Disease (QUIP). Movement Disorders. 2009;24:1461-7.

174. Weintraub D, Mamikonyan E, Papay K, Shea J, Xie S, Siderowf A. Questionnaire for Impulsive-Compulsive Disorders in Parkinson's Disease-Rating Scale. Movement Disorders. 2012;27:242-7.

175. Rieu I, Martinez-Martin P, Pereira B, De Chazeron I, Verhagen Metman L, Jahanshahi M, et al. International validation of a behavioral scale in Parkinson's disease without dementia. Mov Disord. 2015;30(5):705-13.

176. Okai D, Askey-Jones S, Mack J, Martin A, Ray-Chaudhuri K, Samuel M, et al. Parkinson's Impulse Control Scale (PICS) for the rating of severity of impulsive compulsive behaviors in Parkinson's disease. Movement Disorders. 2016;3:494-9.

177. Bastiaens J, Dorfman B, Christos P, Nirenberg M. Prospective cohort study of impulse control disorders in Parkinson's disease. Movement Disorders. 2013;28:327-33.

178. Mamikonyan E, Siderowf A, Duda J, Potenza M, Horn S, Stern $\mathrm{M}$, et al. Long-term follow-up of impulse control disorders in Parkinson's disease. Movement Disorders. 2008;23:75-80. PMCID: PMC17960796.

179. Rabinak C, Nirenberg M. Dopamine agonist withdrawal syndrome in Parkinson disease. Archives of Neurology. 2010;67: 58-63. 
180. Ardouin C, Voon V, Worbe Y, Abouazar N, Czernecki V, Hosseini $\mathrm{H}$, et al. Pathological gambling in Parkinson's disease improves on chronic subthalamic nucleus stimulation. Movement Disorders. 2006;21:1941-6.

181. Abbes M, Lhommee E, Thobois S, Klinger H, Schmitt E, Bichon A, et al. Subthalamic stimulation and neuropsychiatric symptoms in Parkinson's disease: results from a long-term follow-up cohort study. Journal of Neurology, Neurosurgery \& Psychiatry. 2018;89:836-43.

182. Lhommee E, Wojtecki L, Czernecki V, Witt K, Maier F, Tonder $\mathrm{L}$, et al. Behavioural outcomes of subthalamic stimulation and medical therapy versus medical therapy alone for Parkinson's disease with early motor complications (EARLYSTIM trial): secondary analysis of an open-label randomised trial. Lancet Neurol. 2018;17(3):223-31.

183. Lhommée E, Klinger H, Thobois S, Schmitt E, Ardouin C, Bichon A, et al. Subthalamic stimulation in Parkinson's disease: restoring the balance of motivated behaviors. Brain. 2012;135:1463-77.

184. Smeding H, Goudriaan A, Foncke E, Schuurman P, Speelman J, Schmand B. Pathological gambling after bilateral subthalamic nucleus stimulation in Parkinson disease. Journal of Neurology, Neurosurgery and Psychiatry. 2007;78:517-9.

185. Okun M, Weintraub D. Should impulse control disorders and dopamine dysregulation syndrome be indications for deep brain stimulation and intestinal levodopa? Movement Disorders. 2013;28:1915-9.

186. Thomas A, Bonnani L, Gambi F, Di Iorio A, Onofrj M. Pathological gambling in Parkinson disease is reduced by amantadine. Annals of Neurology. 2010;68:400-4.

187. Papay K, Xie SX, Stern M, Hurtig H, Siderowf A, Duda JE, et al. Naltrexone for impulse control disorders in Parkinson disease: a placebo-controlled study. Neurology. 2014;83(9):826-33.

188. Okai D, Askey-Jones S, Samuel M, O'Sullivan S, Chaudhuri K, Martin A, et al. Trial of CBT for impulse control behaviors affecting Parkinson patients and their caregivers. Neurology. 2013;80: 792-9.

189. Voon V, Kubu C, Krack P, Houeto J, Tröster A. Deep brain stimulation: neuropsychological and neuropsychiatric issues. Movement Disorders. 2006;21 (Suppl. 14):S305-S26.

190. Appleby B, Duggan P, Regenberg A, Rabins P. Psychiatric and neuropsychiatric adverse events associated with deep brain stimluation: a meta-analysis of ten years' experience. Movement Disorders. 2007;22:1722-8.

191. Deuschl G, Schade-Brittinger C, Krack P, Volkmann J, Schafer H, Botzel K, et al. A randomized trial of deep-brain stimulation for Parkinson's disease. New England Journal of Medicine. 2006;355: 896-908.

192. Witt K, Daniels C, Reiff J, Krack P, Volkmann J, Pinsker M, et al. Neuropsychological and psychiatric changes after deep brain stimulation for Parkinson's disease: a randomised, multicentre study. Lancet Neurol. 2008;7:605-14.

193. Follett K, Weaver F, Stern M, Hur K, Harris C, Luo P, et al. Pallidal versus subthalamic deep-brain stimulation for Parkinson's disease. New England Journal of Medicine. 2010;362:2077-91.

194. Witjas T, Kaphan E, Azulay J, Blin O, Ceccaldi M, Pouget J, et al. Nonmotor fluctuations in Parkinson's disease: frequent and disabling. Neurology. 2002;59:408-13.

195. Racette B, Hartlein J, Hershey T, Mink J, Perlmutter JS, Black KJ. Clinical features and comorbidity of mood fluctuations in Parkinson's disease. Journal of Neuropsychiatry and Clinical Neurosciences. 2002;14:438-42.

196. Richard I, Justus A, Kurlan R. Relationship between mood and motor fluctuations in Parkinson's disease. Journal of Neuropsychiatry and Clinical Neurosciences. 2001;13:35-41.
197. Kulisevsky J, Pascual-Sedano B, Barbanoj M, Gironell A, Pagonabarraga J, García-Sánchez C. Acute effects of immediate and controlled-release levodopa on mood in Parkinson's disease: a double-blind study. Movement Disorders. 2007;22:62-7.

198. Maricle R, Nutt J, Carter J. Mood and anxiety fluctuation in Parkinson's disease associated with levodopa infusion: preliminary findings. Movement Disorders. 1995;10:329-32.

199. Starkstein S, Mayberg H, Preziosi T, Andrezejewski P, Leiguarda R, Robinson R. Reliability, validity, and clinical correlates of apathy in Parkinson's disease. Journal of Neuropsychiatry and Clinical Neurosciences. 1992;4:134-9.

200. Starkstein S, Merello M, Jorge R, Brockman S, Bruce D, Power B. The syndromic validity and nosological position of apathy in Parkinson's disease. Movement Disorders. 2009;24:1211-6.

201. Kirsch-Darrow L, Fernandez H, Marsiske M, Okun M, Bowers D. Dissociating apathy and depression in Parkinson disease. Neurology. 2006;67:33-8.

202. Isella V, Melzi P, Grimaldi M, Iurlaro S, Piolti R, Ferrarese C, et al. Clinical, neuropsychological, and morphometric correlates of apathy in Parkinson's disease. Movement Disorders. 2002;17: 366-71.

203. Reijnders J, Scholtissen B, Weber W, Aalten P, Verhety F, Leentjens A. Neuroanatomical correlates of apathy in Parkinson's disease: a magnetic resonance imaging study using voxel-based morphometry. Movement Disorders. 2010;25:231825.

204. Thobois S, Lhommee E, Klinger H, Ardouin C, Schmitt E, Bichon A, et al. Parkinsonian apathy responds to dopaminergic stimulation of $\mathrm{D}_{2} / \mathrm{D}_{3}$ receptors with piribedil. Brain. 2013;136:1568-77.

205. Hauser RA, Slawek J, Barone P, Dohin E, Surmann E, Asgharnejad M, et al. Evaluation of rotigotine transdermal patch for the treatment of apathy and motor symptoms in Parkinson's disease. BMC Neurol. 2016;16:90.

206. Devos D, Moreau C, Maltete D, Lefaucheur R, Kreisler A, Eusebio A, et al. Rivastigmine in apathetic but dementia and depression-free patients with Parkinson's disease: a double-blind, placebo-controlled, randomised clinical trial. J Neurol Neurosurg Psychiatry. 2014;85(6):668-74.

207. Phuong L, Garg S, Duda J, Stern M, Weintraub D. Involuntary emotional disorder in Parkinson's disease. Parkinsonism and Related Disorders. 2009;15:511-5.

208. Chattha PK, Greene PE, Ramdhani RA. Pseudobulbar laughter as a levodopa off phenomenon exacerbated by subthalamic deep brain stimulation. J Clin Mov Disord. 2015;2:13.

209. Green R. Regulation of affect. Seminars in Clinical Neuropsychiatry. 1998;3:195-200.

210. Arciniegas D, Topkoff J. The neuropsychiatry of pathologic affect: an approach to evaluation and treatment. Seminars in Clinical Neuropsychiatry. 2000;5:290-306.

211. Panitch H, Thisted R, Smith R, Wynn D, Wymer J, Achiron A, et al. Randomized, controlled trial of dextromethorphan/quinidine for pseudobulbar affect in multiple sclerosis. Annals of Neurology. 2006;59:780-7.

212. Brooks B, Thisted R, Appel S, Bradley W, Olney R, Berg J, et al. Treatment of pseudobulbar affect in ALS with dextromethorphan/ quinidine: a randomized trial. Neurology. 2004;63:1364-70.

213. Sauerbier A, Jenner P, Todorova A, Chaudhuri KR. Non motor subtypes and Parkinson's disease. Parkinsonism Relat Disord. 2016;22 Suppl 1:S41-6.

214. Mavandadi S, Nazem S, Ten Have T, Siderowf A, Duda J, Stern $\mathrm{M}$, et al. Use of latent variable modeling to delineate psychiatric and cognitive profiles in Parkinson's disease. American Journal of Geriatric Psychiatry. 2009;17:986-95.

215. van Rooden S, Visser M, Verbaan D, Marinus J, Van Hilten J. Patterns of motor and non-motor features in Parkinson's disease. 
Journal of Neurology, Neurosurgery and Psychiatry. 2009;80: 846-50.

216. Mu J, Chaudhuri KR, Bielza C, de Pedro-Cuesta J, Larranaga P, Martinez-Martin P. Parkinson's disease subtypes identified from cluster analysis of motor and non-motor symptoms. Front Aging Neurosci. 2017;9:301.

217. Martinez-Martin P. Nonmotor symptoms and health-related quality of life in early Parkinson's disease. Mov Disord. 2014;29(2): 166-8.

218. Chaudhuri K, Martinez-Martin P, Brown R, Sethi K, Stocchi F, Odin $\mathrm{P}$, et al. The metric properties of a novel non-motor symptoms scale for Parkinson's disease: results from an international pilot study. Movement Disorders. 2007;22:1901-11.

219. Visser M, Verbaan D, van Rooden S, Stiggelbout A, Marinus J, Van Hilten J. Assessment of psychiatric complications in Parkinson's disease: The SCOPA-PC. Movement Disorders. 2007;22:2221-8
220. Cummings J, Mega M, Gray K, Rosenberg-Thompson S, Carusi D, Gornbein J. The Neuropsychiatric Inventory: comprehensive assessment of psychopathology in dementia. Neurology. 1994;44: 2308-14.

221. Goetz C, Tilley B, Shaftman S, Stebbins G, Fahn S, MartinezMartin P, et al. Movement Disorder Society-sponsored revision of the Unified Parkinson's Disease Rating Scale (MDS-UPDRS): Scale presentation and climimetric testing results. Movement Disorders. 2008;23:2129-70.

222. Chaudhuri KR, Schrag A, Weintraub D, Rizos A, RodriguezBlazquez C, Mamikonyan E, et al. The Movement Disorder Society Nonmotor Rating Scale: Initial validation study. Mov Disord. 2020;35(1):116-33.

Publisher's Note Springer Nature remains neutral with regard to jurisdictional claims in published maps and institutional affiliations. 